\title{
Estado nutricional e produtividade de algodoeiro em função de diferentes espaçamentos e aplicação de regulador de crescimento
}

\section{Nutritional status and cotton yield under different row spacings and growth regulator application}

\author{
João Vitor Ferrari ${ }^{1 *}$; Enes Furlani Junior²; Samuel Ferrari ${ }^{3}$; \\ Ana Paula Portugal Gouvea Luques ${ }^{4}$
}

\begin{abstract}
Resumo
Estratégias de cultivo do algodoeiro como espaçamento entre linhas e uso de regulador de crescimento são eficientes quando do conhecimento do potencial produtivo da cultura assim como as quantidades de nutrientes absorvidos. O objetivo deste trabalho foi avaliar o estado nutricional do algodoeiro cultivar DeltaOpal por meio da análise foliar de macronutrientes, do índice de clorofila e também a produtividade, em relação ao arranjo de plantas e manejos do regulador de crescimento aplicado. Os tratamentos foram compostos por arranjo de plantas: arranjo 1: 88.900 plantas $\mathrm{ha}^{-1}$ e espaçamento entre linhas de $0,9 \mathrm{~m}$, arranjo 2: 114.300 plantas $\mathrm{ha}^{-1}$ e espaçamento de $0,7 \mathrm{~m}$ e arranjo 3: 178.000 plantas ha $\mathrm{h}^{-1}$ e espaçamento de $0,45 \mathrm{~m}$; e manejo de regulador de crescimento (cloreto de mepiquat), na dose de 1,0 L ha- ${ }^{-1}$, com concentração do i.a. de $50 \mathrm{~g} \mathrm{~L}^{-1}$ : a- sem a aplicação do regulador; b- aplicação única aos 70 dias após a emergência (d.a.e.); c- parcelado em quatro aplicações (aos 35, 45, 55, e 65 d.a.e.). As avaliações de leitura SPAD de clorofila, análise foliar de macronutrientes e produtividade do algodoeiro foram realizadas em três anos agrícolas 2006/07, 2007/08 e 2008/09, sob o delineamento experimental de blocos ao acaso, num esquema fatorial $3 \times 3$ totalizando-se nove tratamentos com quatro repetições. A redução no espaçamento entre linhas com aumento da população de plantas proporciona menor absorção de potássio e enxofre pelo algodoeiro. A utilização do cloreto de mepiquat em dosagem única aumenta os teores foliares de cálcio. A aplicação parcelada do cloreto de mepiquat promove aumento do índice SPAD de clorofila, dos teores foliares de magnésio e da produtividade do algodão em caroço. Palavras-chave: Arranjo de plantas, cloreto de mepiquat, Gossypium hirsutum, nutrição
\end{abstract}

\begin{abstract}
Strategies of cotton growth as row spacing and use of growth regulator are efficient when the knowledge of crop production potential as well as the amounts of nutrients content. The objective of this study was to evaluate the nutritional status of cotton DeltaOpal cultivar through leaf analysis of macronutrient, chlorophyll index and yield in relation to plant arrangement and managements of the growth regulator. The treatments consisted of plant arrangement: arrangement 1: 88,900 plant ha- ${ }^{-1}$ and row spacing at $0.9 \mathrm{~m}$, arrangement 2: 114,300 plant ha $^{-1}$ and row spacing at $0.7 \mathrm{~m}$, arrangement $3: 178,000$ plant ha $^{-1}$ and row spacing at $0.45 \mathrm{~m}$; management of growth regulator (mepiquat chloride) at $1.0 \mathrm{~L} \mathrm{ha}^{-1}$ dose, concentration was $50 \mathrm{~g} \mathrm{~L}^{-1}$ : a- no regulator application; b- single application at 70 days after emergency (d.a.e.); c- split application into four stages $(35,45,55$, and 65 d.a.e.). The reading reviews SPAD chlorophyll, leaf
\end{abstract}

\footnotetext{
${ }^{1}$ Discente do Curso de Doutorado em Agronomia, Universidade Estadual Paulista “Júlio de Mesquita Filho", UNESP, Campus de Ilha Solteira, Ilha Solteira, SP. E-mail: jao_unesp@hotmail.com

2 Prof. Titular, Dept ${ }^{\circ}$ de Fitotecnia, UNESP, Campus de Ilha Solteira, SP. E-mail: enes@agr.feis.unesp.br

3 Prof. Assistente, UNESP, Campus Experimental de Registro, Registro, SP. E-mail: ferrari@registro.unesp.br

${ }^{4}$ M.e em Agronomia pela UNESP, Campus de Ilha Solteira, SP. E-mail: apluques@hotmail.com

* Autor para correspondência
} 
analysis of macronutrients and cotton yield were conducted in three agricultural years 2006/07, 2007/08 and 2008/09, under the experimental design of completely randomized blocks, in a 3x3 factorial scheme totaling up nine treatments with four replications. The reduction of row spacing and increasing plant density gives less absorption of potassium and sulfur by cotton crop. A single application of mepiquat chloride increase calcium leaf content. The split application of mepiquat chloride provides increased SPAD reading index, higher foliar magnesium concentration and highest seed cotton yield.

Key words: Gossypium hirsutum, mepiquat chloride, nutrition, plant arrangement

\section{Introdução}

A cultura do algodoeiro (Gossypium hirsutum L.) é de extrema importância pelo seu valor comercial bem como pela multiplicidade de produtos que dela se originam. É cultivado em cerca de 31,1 milhões de hectares em todo o mundo, sendo o Brasil responsável por uma área de 894,9 mil hectares, com uma produção de 1.260,6 mil toneladas de fibra de algodão na safra 2012/2013. A maior parte da produção brasileira está localizada na região Centro Oeste do Brasil e na Bahia, sendo que os 20 maiores municípios produtores estão localizados em solos do Cerrado (CONAB, 2013).

O algodoeiro é cultura que demanda grandes quantidades de nutrientes para expressar seu potencial produtivo. Estima-se que para produzir $1.000 \mathrm{~kg} \mathrm{ha}^{-1}$ de algodão em caroço, são removidos do solo em média, cerca de 50 a $85 \mathrm{~kg}$ de N, 12 a $26 \mathrm{~kg}$ de $\mathrm{P}_{2} \mathrm{O}_{5}, 43$ a $88 \mathrm{ha}^{-1}$ de $\mathrm{K}_{2} \mathrm{O}, 29$ a $47 \mathrm{~kg}$ de $\mathrm{CaO}, 22$ a $35 \mathrm{~kg}$ de $\mathrm{MgO}$ e 4 a $8 \mathrm{~kg}$ de $\mathrm{S}$ por hectare. Assim, o conhecimento das quantidades de nutrientes absorvidos e exportados pelo algodoeiro, associados à análise do solo, são ferramentas que permitem estimar as doses de fertilizantes a serem aplicadas durante o ciclo da cultura (CARVALHO; FERREIRA, 2006).

O fornecimento de nutrientes via adubação é imprescindível em solos de baixa fertilidade natural (AQUINO et al., 2012), como aqueles de Cerrado, bem como o estudo de manejo cultural e práticas agronômicas que proporcionem adequada formação do algodoeiro.

$\mathrm{Na}$ avaliação do estado nutricional das plantas, vários são os métodos que podem ser utilizados. De acordo com Malavolta, Vitti e Oliveira (1997), as tecnologias empregadas são a diagnose visual, a diagnose foliar e testes bioquímicos entre outros. Dentre esses, a diagnose foliar se destaca, devido a sua aplicabilidade (NEVES et al., 2005). Entretanto, é preciso se considerar a segurança e rapidez dos métodos.

O uso de medidas indiretas para se estabelecer a necessidade de um determinado elemento, como o teor de clorofila na avaliação do estado nutricional de $\mathrm{N}$ das plantas, tem sido muito estudado (FONTES, 2001). O uso do medidor indireto de clorofila SPAD502 tem sido utilizado para diversas culturas, com resultados satisfatórios quanto à avaliação do estado nutricional de N (ZOTARELLI et al., 2003; NEVES et al., 2005; FERREIRA et al., 2006; MADEIRA et al., 2009).

A utilização de reguladores de crescimento é uma tecnologia eficaz no estabelecimento de culturas rentáveis. Quando o algodoeiro cresce sem limitações em umidade do solo e a disponibilidade de nutrientes é adequada, a planta produz vegetação excessiva, o que interfere negativamente na produção final, tornando assim, inevitável o uso de regulador de crescimento (ZANQUETA et al., 2004; BOGIANI; ROSOLEM, 2009; OLIVEIRA et al., 2012). Os efeitos dos reguladores de crescimento, como o cloreto de mepiquat, no algodoeiro, dependem de uma série de fatores, tais como temperatura, espaçamentos e população de plantas, época de semeadura, cultivar e adubação (CARVALHO et al., 1994).

O algodoeiro é uma planta que apresenta elevada plasticidade fenotípica (BELTRÃO; AZEVEDO 1993), adequando-se aos mais variados ambientes tendo, evidentemente, os requerimentos ideais de 
clima e solo para chegar a produtividades elevadas e à fibra de qualidade (SOUZA; BELTRÃO, 1999). Trata-se de uma planta complexa do ponto de vista anatômico e fisiológico. Ela apresenta dimorfismo de ramos, isto é, ramo monopodial ou vegetativo e ramo simpodial ou frutífero (BELTRÃO; AZEVEDO, 1993). O algodoeiro detém estruturas planofilares, ou seja, ramos e folhas horizontalizados, o que dificulta o uso de densidades populacionais mais elevadas (AZEVEDO et al., 2004). No tocante ao manejo cultural dos agrossistemas, os fatores população de plantas e adubação assumem papel importante para atingir elevadas produtividades de algodão em pluma, e a respostas das cultivares podem ser diferentes, dependendo de fatores internos e externos das plantas (ZANQUETA et al., 2004).

Desta forma o objetivo deste trabalho foi avaliar o estado nutricional do algodoeiro cultivar DeltaOpal por meio da análise foliar de macronutrientes e da utilização do medidor portátil de clorofila SPAD502, como também a sua produtividade, em relação aos diferentes espaçamentos e manejos do regulador de crescimento aplicado.

\section{Material e Métodos}

Para o estudo, os experimentos foram conduzidos nos anos agrícolas de 2006/07, 2007/08 e 2008/09, no município de Selvíria-MS, (20²2'S, $51^{\circ} 22^{\prime} \mathrm{W}$ e altitude média de $335 \mathrm{~m}$ ). O clima da região é do tipo Aw, segundo a classificação de Köeppen, com temperatura média anual de $23,5^{\circ}$ C, umidade relativa do ar média anual entre $60 \%$ e $70 \%$ e precipitação pluvial média anual de 1370 $\mathrm{mm}$. O solo da área experimental foi classificado como Latossolo Vermelho distrófico típico textura argilosa, conforme a classificação brasileira de solos (SANTOS et al., 2006).

A cada dois anos foram retiradas amostras de solo para caracterização das propriedades químicas, sendo realizadas em junho de 2006 e agosto de 2008 seguindo metodologia de análise descrita por
Raij e Quaggio (1983), que revelou os seguintes valores em 2006: $\mathrm{pH}\left(\mathrm{CaCl}_{2}\right)=4,9 ; \mathrm{P}_{\text {resina }}=10 \mathrm{mg}$ $\mathrm{dm}^{-3}$; M.O. $=24 \mathrm{~g} \mathrm{dm}^{-3} ; \mathrm{K}^{+}=4,6 \mathrm{mmol}_{\mathrm{c}} \mathrm{dm}^{-3} ; \mathrm{Ca}^{+2}=$ $18 \mathrm{mmol}_{\mathrm{c}} \mathrm{dm}^{-3} ; \mathrm{Mg}^{+2}=10 \mathrm{mmol}_{\mathrm{c}} \mathrm{dm}^{-3} ; \mathrm{H}+\mathrm{Al}=24$ $\mathrm{mmol}_{\mathrm{c}} \mathrm{dm}^{-3} ; \mathrm{Al}=0 \mathrm{mmol}_{\mathrm{c}} \mathrm{dm}^{-3} ; \mathrm{CTC}=57 \mathrm{mmol}_{\mathrm{c}}$ $\mathrm{dm}^{-3} ; \mathrm{V}=57 \%$. Já em 2008 os valores da análise de solo foram: $\mathrm{pH}\left(\mathrm{CaCl}_{2}\right)=4,8 ; \mathrm{P}_{\text {resina }}=11 \mathrm{mg} \mathrm{dm}^{-}$ 3; M.O. $=22 \mathrm{~g} \mathrm{dm}^{-3} ; \mathrm{K}^{+}=4,8 \mathrm{mmol}_{\mathrm{c}} \mathrm{dm}^{-3} ; \mathrm{Ca}^{+2}=$ $22 \mathrm{mmol}_{\mathrm{c}} \mathrm{dm}^{-3} ; \mathrm{Mg}^{+2}=14 \mathrm{mmol}_{\mathrm{c}} \mathrm{dm}^{-3} ; \mathrm{H}+\mathrm{Al}=21$ $\mathrm{mmol}_{\mathrm{c}} \mathrm{dm}^{-3} ; \mathrm{Al}=0 \mathrm{mmol}_{\mathrm{c}} \mathrm{dm}^{-3} ; \mathrm{CTC}=59 \mathrm{mmol}_{\mathrm{c}}$ $\mathrm{dm}^{-3} ; \mathrm{V}=59 \%$.

No ano de 2005, a área utilizada foi cultivada com algodão em sistema convencional. Para o ano agrícola 2006/07 a semeadura foi em sistema de semeadura direta na palha utilizando-se o milheto como cultura antecessora para obtenção de palha na área. Essa cultura foi escolhida por apresentar boa produção de matéria seca (CÖSER; MARASCHIN, 1981; GUIDELI; FAVORETO; MALHEIRIOS, 2000). Para os demais anos agrícolas (2007/08 e 2008/09), a instalação do experimento continuou sendo por meio de semeadura direta sobre a palha do milheto.

O delineamento experimental empregado foi fatorial $3 \times 3$, dispostos em blocos ao acaso, obtendose nove tratamentos, com quatro repetições, num total de 36 parcelas. Os fatores foram compostos por arranjo de plantas: arranjo 1: 88.900 plantas ha $^{-1}$ e espaçamento entre linhas de $0,9 \mathrm{~m}$, arranjo 2 : 114.300 plantas ha $^{-1}$ e espaçamento de $0,7 \mathrm{~m}$ e arranjo 3: 178.000 plantas $^{-1} \mathrm{a}^{-1}$ e espaçamento de $0,45 \mathrm{~m}$; e manejo do regulador de crescimento (cloreto de mepiquat) na dose de 1,0 $\mathrm{L} \mathrm{ha}^{-1}$, com concentração do i.a. de $50 \mathrm{~g} \mathrm{~L}^{-1}$, sendo: a- sem a aplicação do regulador; b- com aplicação do regulador em aplicação única aos 70 dias após a emergência (d.a.e.); c- com aplicação do regulador parcelado em quatro aplicações (aos 35, 45, 55, e 65 d.a.e.). A aplicação do regulador de crescimento via foliar foi realizada em jato dirigido, com pulverizador de pesquisa, costal com pressurização a $\mathrm{CO}_{2}$, barra de alumínio e pressão constante, e bico hidráulico, tipo jato cônico vazio e vazão de $200 \mathrm{~L} \mathrm{ha}^{-1}$ conforme 
tratamentos estabelecidos e realizadas no período matutino no intuito de evitar altas temperaturas no momento da aplicação.

Para a instalação dos experimentos nos três anos agrícolas, foi utilizado a cultivar de algodoeiro DeltaOpal, por apresentar grande adaptação em várias regiões de cultivo, forma cônica, ciclo de desenvolvimento de até 160 dias, necessita de uso de regulador de crescimento, pois pode chegar até a 1,6 m de altura, apresenta resistência a viroses e bacterioses. A semeadura do algodoeiro nos três anos agrícolas foi realizada com auxílio de semeadora adubadora no mês de novembro de 2006, 2007 e 2008 respectivamente, com tratamento das sementes de algodão utilizando-se fungicida Vitavax/Thiran $200+200(100+100 \mathrm{~g}$ i.a. para $100 \mathrm{~kg}$ semente $)$ e inseticida Tiametoxam (210g i.a. para $100 \mathrm{~kg}$ semente). Cada parcela experimental foi composta por quatro linhas de cultivo, com cinco metros de comprimento, sendo a área útil constituída pelas duas linhas centrais da parcela. Após a emergência e estabelecimento das plantas (15 d.a.e.) estas foram desbastadas, deixando-se 8 plantas por metro em todos os tratamentos, atendendo os tratamentos em estudo.

A adubação básica de semeadura seguiu as recomendações de Silva e Raij (1997) e contou com $200 \mathrm{~kg} \mathrm{ha}^{-1}$ da formulação 08-28-16 (N, P e $\mathrm{K}$ respectivamente) aplicada na semeadura. Para a adubação de cobertura foi utilizado $60 \mathrm{~kg} \mathrm{ha}^{-1}$ de $\mathrm{N}$ divididas igualmente em duas aplicações aos $35 \mathrm{e}$ 55 d.a.e. Na primeira aplicação a fonte utilizada foi uréia $(45 \% \mathrm{~N})$ e na segunda utilizou-se o sulfato de amônio (21\% de $\mathrm{N}$ e $24 \%$ de S).

Para emergência e estabelecimento das plantas de algodoeiro (até 20 d.a.e.) foram realizadas irrigações com $20 \mathrm{~mm}$ de água sempre que necessário, por meio de irrigação do tipo auto propelido equipado com canhão aspersor. O controle de plantas daninhas, insetos e doenças foram realizados por meio de manejo químico de acordo com a necessidade da cultura durante o ciclo.
Foram avaliados, nos três anos agrícolas, o estado nutricional, o índice SPAD de clorofila e a produtividade do algodoeiro. Como forma de avaliação do estado nutricional, foi realizada análise dos teores de macronutrientes contido nas folhas que foram coletadas aos 80 dias após emergência das plântulas, seguindo as recomendações de Silva (1999). A coleta das folhas coincidiu com a época de maior absorção dos nutrientes pelas folhas do algodoeiro. Para Rosolem (2001) a marcha de absorção dos nutrientes pelo algodoeiro, segue o padrão de crescimento, aumentando consideravelmente a partir dos 30 dias da semeadura, coincidindo com a emissão dos primeiros botões florais, alcançando uma absorção máxima diária na fase de florescimento entre 60 e 90 dias após a germinação dependendo da cultivar. Após a coleta, estas foram encaminhadas ao laboratório de análise foliar onde seguiram as metodologias relatadas por Malavolta, Vitti e Oliveira (1997). Ainda como forma de avaliar o estado nutricional das plantas, foi utilizado o medidor portátil de clorofila (clorofilômetro) SPAD-502, para leituras dos índices SPAD de clorofila, realizada também aos 80 dias após a emergência.

No mês de abril de 2007, 2008 e 2009, aos 150 e aos 152 e 149 d.a.e. respectivamente, foram realizadas a colheita de algodão na área útil das parcelas, para quantificar a produção de algodão em caroço. Esta foi realizada manualmente sendo na sequencia pesados com auxilio de balança digital e realizados os cálculos para produtividade $\left(\mathrm{kg} \mathrm{ha}^{-1}\right.$ de algodão em caroço). Após a colheita da área experimental foi realizada a destruição da soqueira do algodoeiro com auxílio de roçadora.

Os dados obtidos em cada ano agrícola de estudo foram submetidos à análise de variância por meio de teste $\mathrm{F}$ e teste de Tukey a $5 \%$ de probabilidade utilizando a metodologia descrita por Banzatto e Kronka (2006) e programa SISVAR versão 5.3 (FERREIRA, 2011). 


\section{Resultados e Discussão}

Nas Tabelas 1, 2 e 3 foram apresentados os teores médios dos macronutrientes para os três anos agrícolas, obtidos pela análise foliar realizada aos 80 d.a.e., para diferentes espaçamentos e manejos do regulador de crescimento.

Os arranjos de plantas a que foram submetidas plantas de algodoeiro não proporcionaram alterações significativas nas concentrações foliares de N, P, Ca e Mg. Para Rosolem et al. (2012) ao estudarem arranjos de plantas para a cv. FM 966 LL muito semelhante a esse estudo não proporcionaram alterações nas concentrações finais dos nutrientes N e P. Para o ano agrícola 2006/07 (Tabela 1), constatou-se que as plantas instaladas em espaçamento de $0,70 \mathrm{~m}$ e população de 114.300 plantas apresentaram maiores teores foliares de potássio, quando comparadas às plantas submetidas ao espaçamento menor. O potássio pode ser requerido pelo algodoeiro em quantidades semelhantes à de nitrogênio, podendo ser extraído do solo a taxas de até $5,6 \mathrm{~kg} \mathrm{ha}^{-1}$ dia $^{-1}$ durante as fases de florescimento e frutificação (CASSMAN, 1993), determinando sua importância para a planta. Porém, o acúmulo deste nutriente pelas folhas pode variar de acordo com o espaçamento utilizado. Assim, plantas submetidas a espaçamentos menores e maior população de plantas estão mais sujeitas à competição, absorvendo menor quantidade desse nutriente, sendo imprescindível neste caso uma adubação potássica maior, principalmente em solos com condições de fertilidade baixa/média. Para os anos agrícolas 2007/08 e 2008/09 (Tabelas 2 e 3), os diferentes espaçamentos e populações de plantas influenciaram significativamente a absorção de enxofre. Verificou-se que as plantas conduzidas nos espaçamentos de $0,90 \mathrm{~m}$ e $0,70 \mathrm{~m}$ apresentaram maiores teores foliares, resultado da menor população e menor competição entre plantas, com consequente maior aproveitamento do nutriente. Dessa forma a realização de adubação diferenciada para cada realidade de arranjo de plantas utilizado na cultura do algodoeiro se faz necessária.

Analisando os dados das Tabelas 1 e 2 com relação ao manejo de aplicação de cloreto de mepiquat, verificou-se que apenas os teores foliares de $\mathrm{Mg}$ apresentaram diferenças significativas em resposta a aplicação do produto, sendo os maiores teores encontrados para a forma parcelada de aplicação. Tais resultados podem ser explicados devido ao algodoeiro apresentarem maiores teores foliares de clorofila (sendo o Mg é um dos nutrientes constituintes dessa molécula, TAIZ; ZEIGER, 2009), quando submetido ao tratamento com aplicações de cloreto de mepiquat. Esse incremento pode ser percebido até 20 dias após a aplicação (REDDY; REDDY; HODGES, 1996). Em nível de campo tais resultados podem ser observados pela tonalidade mais escura das folhas do algodoeiro que receberam a aplicação de regulador de crescimento de forma parcelada.

Com relação ao terceiro ano agrícola (Tabela 3), verificou-se que a aplicação única do cloreto de mepiquat proporcionou maiores teores foliares de cálcio quando comparadas à não aplicação do produto, indicando que plantas com menor desenvolvimento vegetativo proporcionado pela ação do produto revela incremento dos teores de $\mathrm{Ca}$ nas folhas. Os teores foliares dos demais nutrientes não apresentaram diferenças estatísticas para este fator estudado, inferindo que a capacidade de absorção da cultivar DeltaOpal para os demais nutrientes foi a mesma. 
Tabela 1. Análise foliar de macronutrientes do algodoeiro cultivar DeltaOpal, aos 80 d.a.e. em função de arranjo de plantas e manejo de cloreto de mepiquat, Selvíria-MS, Ano agrícola 2006/07.

\begin{tabular}{|c|c|c|c|c|c|c|c|c|c|}
\hline \multirow{2}{*}{ Tratamentos } & \multicolumn{9}{|c|}{ Macronutrientes $\left(\mathrm{g} \mathrm{kg}^{-1}\right)$} \\
\hline & $\mathbf{N}$ & $\mathbf{P}$ & $\mathbf{K}$ & & Ca & Mg & & $S$ & \\
\hline & \multicolumn{9}{|c|}{ Teste F } \\
\hline Arranjo de plantas (A) & 0,58 & 0,49 & & $5 *$ & 1,31 & $1, \varepsilon$ & & & 2,36 \\
\hline Regulador (R) & 1,03 & 1,00 & 0 , & & 2,23 & 3, & & $*$ & 0,24 \\
\hline \multirow[t]{2}{*}{$(A * R)$} & 0,52 & 0,25 & & & 0,81 & 1,2 & & & 0,47 \\
\hline & \multicolumn{9}{|c|}{ Teste Tukey } \\
\hline \multicolumn{10}{|l|}{ Arranjo de plantas } \\
\hline 1 & 41,93 & 4,52 & 12,87 & $\mathrm{ab}$ & 18,21 & 4,74 & & & 8,85 \\
\hline 2 & 43,97 & 4,26 & 14,18 & $\mathrm{a}$ & 20,76 & 4,87 & & & 9,85 \\
\hline 3 & 43,70 & 4,13 & 7,66 & $\mathrm{~b}$ & 18,60 & 4,21 & & & 7,54 \\
\hline \multicolumn{10}{|l|}{ Regulador } \\
\hline a & 43,15 & 4,59 & 10,65 & & 17,38 & 4,10 & $\mathrm{~b}$ & & 9,04 \\
\hline $\mathrm{b}$ & 41,74 & 4,32 & 12,31 & & 19,24 & 4,59 & $a b$ & & 8,87 \\
\hline $\mathrm{c}$ & 44,71 & 4,01 & 11,74 & & 20,95 & 5,12 & $\mathrm{a}$ & & 8,34 \\
\hline C.V.(\%) & 11,70 & 15,13 & 45,97 & & 21,64 & 19,20 & & & 29,84 \\
\hline D.M.S. & 5,16 & 0,66 & 5,42 & & 4,23 & 0,90 & & & 2,66 \\
\hline
\end{tabular}

Médias seguidas da mesma letra na vertical não diferem entre si pelo teste de Tukey, ao nível de 5\% de probabilidade.

**, * Significativos aos níveis de 1 e 5 \% respectivamente pelo teste de F da análise da variância.

Fonte: Elaboração dos autores.

Tabela 2. Análise foliar de macronutrientes do algodoeiro cultivar DeltaOpal, aos 80 d.a.e. em função de arranjo de plantas e manejo de cloreto de mepiquat, Selvíria-MS, Ano agrícola 2007/08.

\begin{tabular}{|c|c|c|c|c|c|c|c|c|}
\hline \multirow{2}{*}{ Tratamentos } & \multicolumn{8}{|c|}{ Macronutrientes $\left(\mathrm{g} \mathrm{kg}^{-1}\right)$} \\
\hline & $\mathbf{N}$ & $\mathbf{P}$ & K & $\mathrm{Ca}$ & Mg & & $\begin{array}{l}\mathbf{S} \\
\end{array}$ & \\
\hline & \multicolumn{8}{|c|}{ Teste $\mathbf{F}$} \\
\hline Arranjo de plantas (A) & 0,51 & 1,58 & 2,88 & 1,04 & 1,98 & & 8,33 & $* *$ \\
\hline Regulador (R) & 1,49 & 1,79 & 0,04 & 0,40 & 6,41 & $* *$ & 1,20 & \\
\hline$(A * R)$ & 0,15 & 0,58 & 0,51 & 0,67 & 0,21 & & 1,23 & \\
\hline \multicolumn{9}{|c|}{ Teste Tukey } \\
\hline \multicolumn{9}{|l|}{ Arranjo de plantas } \\
\hline 1 & 46,27 & 4,63 & 12,71 & 18,50 & 4,66 & & 9,49 & $\mathrm{a}$ \\
\hline 2 & 44,45 & 4,47 & 11,94 & 19,68 & 4,53 & & 10,43 & $\mathrm{a}$ \\
\hline 3 & 44,67 & 4,12 & 8,67 & 17,93 & 4,05 & & 7,45 & $\mathrm{~b}$ \\
\hline \multicolumn{9}{|l|}{ Regulador } \\
\hline $\mathrm{a}$ & 43,76 & 4,62 & 10,88 & 18,50 & 3,81 & $\mathrm{~b}$ & 8,89 & \\
\hline $\mathrm{b}$ & 44,62 & 4,51 & 11,40 & 19,33 & 4,47 & $a b$ & 9,76 & \\
\hline $\mathrm{c}$ & 47,02 & 4,09 & 11,04 & 18,28 & 4,96 & $\mathrm{a}$ & 8,63 & \\
\hline C.V.(\%) & 10,61 & 16,49 & 39,42 & 16,25 & 17,89 & & 20,09 & \\
\hline D.M.S. & 4,88 & 0,74 & 4,47 & 3,10 & 0,81 & & 1,87 & \\
\hline
\end{tabular}

Médias seguidas da mesma letra na vertical não diferem entre si pelo teste de Tukey, ao nível de 5\% de probabilidade.

** , Significativos aos níveis de 1 e 5 \% respectivamente pelo teste de F da análise da variância.

Fonte: Elaboração dos autores. 
Tabela 3. Análise foliar de macronutrientes do algodoeiro cultivar DeltaOpal, aos 80 d.a.e. em função de arranjo de plantas e manejo de cloreto de mepiquat, Selvíria-MS, Ano agrícola 2008/09.

\begin{tabular}{|c|c|c|c|c|c|c|c|c|}
\hline \multirow{2}{*}{ Tratamentos } & \multicolumn{8}{|c|}{ Macronutrientes $\left(\mathrm{g} \mathrm{kg}^{-1}\right)$} \\
\hline & $\mathbf{N}$ & $\mathbf{P}$ & $\mathbf{K}$ & $\mathbf{C a}$ & & Mg & $\mathbf{S}$ & \\
\hline & \multicolumn{8}{|c|}{ Teste F } \\
\hline Arranjo de plantas (A) & 0,21 & 0,23 & 1,46 & 1,16 & & 0,19 & 5,48 & $*$ \\
\hline Regulador (R) & 2,32 & 1,39 & 0,82 & 5,55 & * & 3,05 & 1,57 & \\
\hline$(A * R)$ & 0,08 & 0,86 & 0,44 & 0,62 & & 0,54 & 0,36 & \\
\hline \multicolumn{9}{|c|}{ Teste Tukey } \\
\hline \multicolumn{9}{|l|}{ Arranjo de plantas } \\
\hline 1 & 43,05 & 4,33 & 6,65 & 15,30 & & 4,54 & 5,22 & $\mathrm{a}$ \\
\hline 2 & 43,76 & 4,32 & 6,90 & 16,46 & & 4,48 & 4,74 & $\mathrm{ab}$ \\
\hline 3 & 44,04 & 4,21 & 5,73 & 15,39 & & 4,42 & 4,20 & $\mathrm{~b}$ \\
\hline \multicolumn{9}{|l|}{ Regulador } \\
\hline $\mathrm{a}$ & 41,68 & 4,23 & 6,74 & 14,16 & $\mathrm{~b}$ & 4,33 & 4,48 & \\
\hline $\mathrm{b}$ & 44,28 & 4,17 & 5,89 & 16,90 & $\mathrm{a}$ & 4,75 & 5,02 & \\
\hline $\mathrm{c}$ & 44,90 & 4,46 & 6,65 & 16,10 & $a b$ & 4,36 & 4,65 & \\
\hline C.V.(\%) & 8,91 & 10,74 & 27,62 & 13,17 & & 10,46 & 16,12 & \\
\hline D.M.S. & 3,96 & 0,47 & 1,81 & 2,11 & & 0,48 & 0,78 & \\
\hline
\end{tabular}

Médias seguidas da mesma letra na vertical não diferem entre si pelo teste de Tukey, ao nível de 5\% de probabilidade. **,${ }^{*}$ Significativos aos níveis de 1 e $5 \%$ respectivamente pelo teste de $\mathrm{F}$ da análise da variância.

Fonte: Elaboração dos autores.

Na Tabela 4 são apresentados os valores médios do índice SPAD de clorofila da cv. Deltaopal em condição de Cerrado para os três anos agrícolas. Os resultados obtidos para o primeiro ano agrícola estudado (2006/07) evidenciam que o arranjo de plantas influenciam diretamente nas leituras do índice SPAD, sendo que o espaçamento de $0,90 \mathrm{~m}$ e população de plantas de 88.900 promoveram maiores valores nas leituras quando comparado ao espaçamento $0,70 \mathrm{~m}$ entre linhas e população de 114.300 planas ha ${ }^{-1}$, efeito da menor competição entre plantas promovido pelo maior arranjo.

Ao se analisar o efeito do cloreto de mepiquat, verificou-se que nos dois últimos anos agrícolas, a forma parcelada de aplicação proporcionou aumento na leitura do índice SPAD quando comparadas a não aplicação. Tais resultados manifestam que as plantas tratadas com regulador de crescimento apresentam maior capacidade fotossintética refletindo em maiores leituras do índice SPAD, podendo resultar em maiores produtividades. Esta maior capacidade de realizar fotossíntese devido o uso de cloreto de mepiquat também foi encontrado por Souza (2007) e Rosolem, Oosterhuis e Souza (2013), que obtiveram valores maiores de índice SPAD de clorofila em diferentes leituras após a aplicação do cloreto de mepiquat em plantas de algodoeiro em casa de vegetação. Reddy, Reddy e Hodges (1996) relatam que há um aumento no conteúdo de clorofila em plantas tratadas com cloreto de mepiquat, indicativo do aumento do valor do índice SPAD, o qual está relacionado com o conteúdo de clorofila presente na folha. Segundo Hodges, Reddy e Reddy (1991), o cloreto de mepiquat influencia o crescimento, a respiração e a fotossíntese, podendo essa ter maior eficiência em função da redução da fotorrespiração em plantas tratadas com o produto. A utilização de cloreto de mepiquat como regulador do crescimento é eficiente principalmente por ser absorvido pelas partes verdes da planta e também por ser incluído no grupo de inibidores da biossíntese do ácido giberélico (TAIZ; ZEIGER, 2009; NAGASHIMA et al., 2010; ROSOLEM; OOSTERHUIS; SOUZA, 2013). 
Tabela 4. Índice SPAD de clorofila no algodoeiro cultivar DeltaOpal, aos 80 d.a.e em função de arranjo de plantas e manejo de cloreto de mepiquat. Selvíria-MS, Anos agrícolas 2006/07, 2007/08 e 2008/09.

\begin{tabular}{|c|c|c|c|c|c|c|}
\hline \multirow{2}{*}{ Tratamentos } & \multicolumn{6}{|c|}{ Índice SPAD } \\
\hline & \multicolumn{2}{|l|}{$2006 / 2007$} & \multicolumn{2}{|l|}{$2007 / 2008$} & \multicolumn{2}{|c|}{$2008 / 2009$} \\
\hline & \multicolumn{6}{|c|}{ Teste $\mathbf{F}$} \\
\hline Arranjo de plantas (A) & 7,97 & $* *$ & 1,00 & & 1,98 & \\
\hline Regulador (R) & 2,35 & & 4,39 & * & 8,47 & $* *$ \\
\hline$(A * R)$ & 1,05 & & 1,18 & & 0,67 & \\
\hline \multicolumn{7}{|c|}{ Teste Tukey } \\
\hline \multicolumn{7}{|l|}{ Arranjo de plantas } \\
\hline 1 & 52,15 & $\mathrm{a}$ & 50,81 & & 48,23 & \\
\hline 2 & 45,43 & $\mathrm{~b}$ & 49,60 & & 47,06 & \\
\hline 3 & 47,90 & $\mathrm{ab}$ & 49,38 & & 46,07 & \\
\hline \multicolumn{7}{|l|}{ Regulador } \\
\hline $\mathrm{a}$ & 46,57 & & 48,63 & $\mathrm{~b}$ & 44,78 & $\mathrm{~b}$ \\
\hline $\mathrm{b}$ & 48,66 & & 49,42 & $\mathrm{ab}$ & 47,34 & $\mathrm{ab}$ \\
\hline $\mathrm{c}$ & 50,25 & & 51,73 & $\mathrm{a}$ & 49,24 & $\mathrm{a}$ \\
\hline C.V.(\%) & 8,60 & & 5,34 & & 27,62 & \\
\hline D.M.S. & 4,26 & & 2,72 & & 1,81 & \\
\hline
\end{tabular}

Médias seguidas da mesma letra não diferem entre si pelo teste de Tukey, ao nível de $5 \%$ de probabilidade.

**, * Significativos aos níveis de 1 e 5 \% respectivamente pelo teste de F da análise da variância.

Fonte: Elaboração dos autores.

$\mathrm{Na}$ Tabela 5 foram apresentados os valores de produtividade obtidos para a cultivar DeltaOpal em três anos agrícolas em função de diferentes arranjo de plantas e manejos do regulador de crescimento. Avaliando-se os dois primeiros anos agrícolas verificou-se que os diferentes arranjos de plantas em estudo não alteraram significativamente a produtividade do algodoeiro. Tais resultados concordam com os encontrados por Clawson, Cothren e Blouin (2006), que ao estudarem no estado do Texas três diferentes arranjo de plantas com espaçamentos entre linhas para a cultura do algodoeiro de 0,$19 ; 0,38$ e 0,76m não encontraram diferenças significativas para a produtividade de fibra.

Ainda com a análise dos dados apresentados na Tabela 5 referentes à produtividade, no último ano agrícola (2008/09), observou-se que o algodoeiro cultivado em arranjo de plantas com espaçamento entre linhas de $0,45 \mathrm{~m}$ e população de 178.000 plantas $\mathrm{ha}^{-1}$, sendo este com maior adensamento de plantas em estudo apresentaram maior produtividade quando comparadas com aquelas em arranjo de plantas instalado em espaçamento entre linhas de $0,7 \mathrm{~m}$, demonstrando que a cultivar DeltaOpal tem capacidade de se adaptar a diferentes arranjos, obtendo maior produtividade em resposta ao aumento da população de plantas e consequente maior aproveitamento dos recursos disponíveis no meio. Pesquisas demonstram vantagens para a produtividade de fibra de algodão nos arranjos de plantas com menores espaçamentos entre linhas quando comparado com os espaçamentos convencionais, como Silva (2002) que trabalhando com espaçamentos entre linhas $(0,38 ; 0,76$ e $0,95 \mathrm{~m})$ e densidades de plantas por metro linear $(5,8$, 11, e 14) para a cv. IAC 23 encontrou produção de algodão em caroço de $12 \%$ e $8,4 \%$ superior nos espaçamentos entre linhas ultra-adensado e adensado, respectivamente, quando comparado ao convencional. 
Tabela 5. Produtividade do algodão em caroço cultivar DeltaOpal, em função de arranjo de plantas e manejo de cloreto de mepiquat. Selvíria-MS, Anos agrícolas 2006/07, 2007/08 e 2008/09.

\begin{tabular}{|c|c|c|c|c|c|c|}
\hline \multirow{2}{*}{ Tratamentos } & \multicolumn{6}{|c|}{ Produtividade $\left(\mathrm{Kg} \mathrm{ha}^{-1}\right)$} \\
\hline & $2006 / 2007$ & & $2007 / 2008$ & & $2008 / 2009$ & \\
\hline & \multicolumn{6}{|c|}{ Teste $\mathbf{F}$} \\
\hline Arranjo de plantas (A) & 2,03 & & 0,50 & & 3,89 & $*$ \\
\hline Regulador (R) & 5,84 & $* *$ & 3,58 & $*$ & 0,65 & \\
\hline \multirow[t]{2}{*}{$(A * R)$} & 0,47 & & 0,19 & & 1,13 & \\
\hline & \multicolumn{6}{|c|}{ Teste Tukey } \\
\hline \multicolumn{7}{|l|}{ Arranjo de plantas } \\
\hline 1 & 1519,83 & & 1941,75 & & 2900,49 & $a b$ \\
\hline 2 & 1354,33 & & 1859,33 & & 2446,98 & $\mathrm{~b}$ \\
\hline 3 & 1274,33 & & 1905,33 & & 3163,04 & $\mathrm{a}$ \\
\hline \multicolumn{7}{|l|}{ Regulador } \\
\hline $\mathrm{a}$ & 1161,08 & $\mathrm{~b}$ & 1778,00 & $\mathrm{~b}$ & 2447,32 & \\
\hline $\mathrm{b}$ & 1403,17 & $a b$ & 1924,25 & $a b$ & 3008,34 & \\
\hline $\mathrm{c}$ & 1584,25 & $\mathrm{a}$ & 2004,17 & $\mathrm{a}$ & 2754,85 & \\
\hline C.V.(\%) & 22,01 & & 10,61 & & 22,43 & \\
\hline D.M.S. & 310,37 & & 205,79 & & 648,84 & \\
\hline
\end{tabular}

Médias seguidas da mesma letra na vertical não diferem entre si pelo teste de Tukey, ao nível de 5\% de probabilidade.

**, * Significativos aos níveis de 1 e 5 \% respectivamente pelo teste de $\mathrm{F}$ da análise da variância.

Fonte: Elaboração dos autores.

Analisando-se os diferentes modos de aplicação do cloreto de mepiquat, (Tabela 5), constatou-se que somente no ano agrícola 2008/09 não foram observados resultados influenciados pela forma de aplicação do produto. Já para os demais anos em estudo (2006/07 e 2007/08), verificaram-se maiores produtividades onde a aplicação de regulador de crescimento foi realizada de forma parcelada em relação à testemunha. A maior produtividade encontrada deve estar relacionada com a eficiência que o cloreto de mepiquat possui em promover abertura mais uniforme das estruturas reprodutivas, uma vez que o regulador de crescimento, ao reduzir o desenvolvimento vegetativo da planta, promove redirecionamento das reservas para $o$ desenvolvimento reprodutivo, afetando assim a produtividade no momento da colheita. Para Meredith Junior e Wells (1989), essa redução da taxa de crescimento vegetativo é vantajosa, pois assim tem-se plantas em que a relação da matéria seca da parte reprodutiva e vegetativa é maior que uma unidade, correlacionando-se positivamente com a produtividade do algodoeiro.
A produtividade na safra 2008/2009 foi superior àquela obtida em 2007/2008, que por sua vez foi superior à de 2006/2007, podendo essas relações serem atribuídas à quantidade adequada de chuvas que ocorrem em 2008/2009 e $2007 / 2008$, indicando que a cultura do algodoeiro apresenta adequado desenvolvimento reprodutivo em condições de maior precipitação pluvial. As chuvas entre novembro de 2006 e abril de 2007 acumularam 960,34 $\mathrm{mm}$ de água, quantidade essa menor do que no ano agrícola seguinte, que foi de aproximadamente 1280,40 $\mathrm{mm}$ de água. Enquanto que as chuvas entre novembro de 2008 e abril de 2009 acumularam 1.158,34 mm de água. Além das quantidades de chuvas a distribuição foi melhor nos anos agrícolas de 2007/2008 e 2008/2009 com maiores quantidades entre os meses de janeiro a março, época de grande absorção de nutrientes e consequente desenvolvimento reprodutivo (Figura $1 \mathrm{a}, 1 \mathrm{~b}$ e $1 \mathrm{c}$ e $1 \mathrm{~d})$. 
Figura 1. Precipitação pluvial e temperaturas médias, no período de janeiro a dezembro dos anos de 2006 (a), 2007 (b), 2008 (c) e 2009 (d). Selvíria-MS.

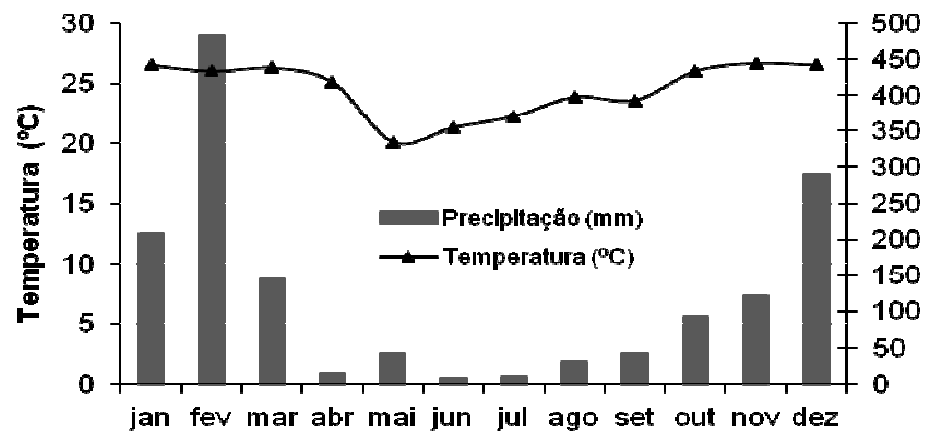

meses

(a)

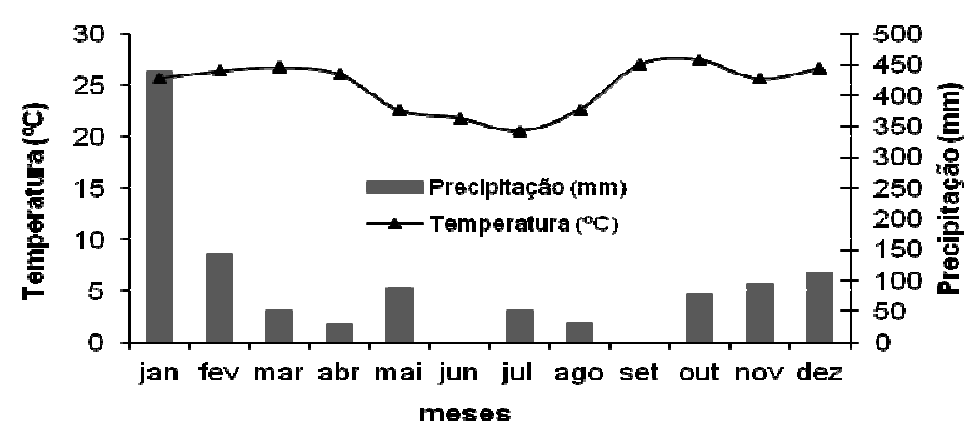

(b)
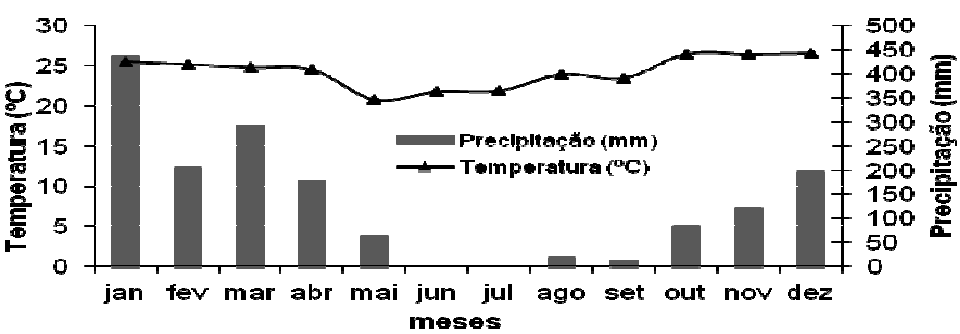

(c)

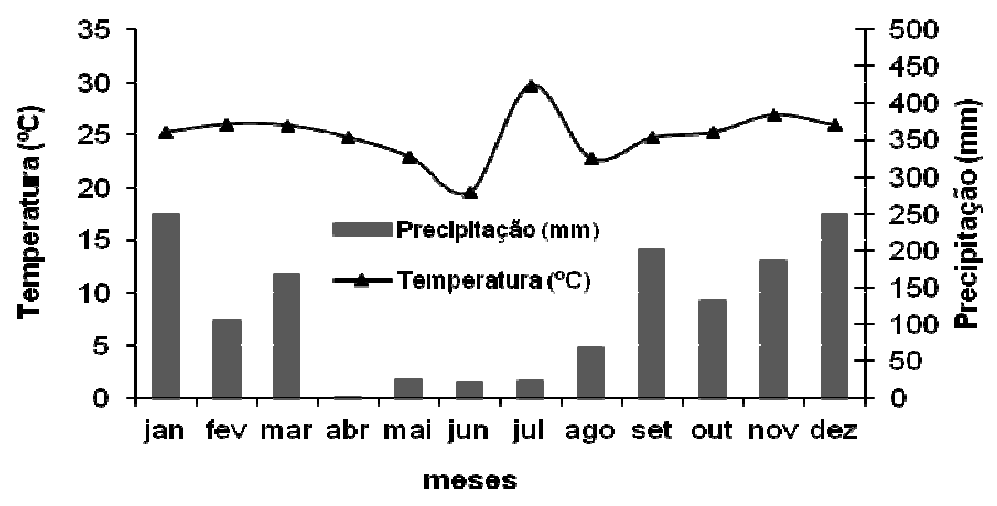

(d)

Fonte: Elaboração dos autores. 


\section{Conclusões}

A redução no espaçamento entre linhas com aumento da população de plantas proporciona menor absorção de potássio e enxofre pelo algodoeiro.

A utilização do cloreto de mepiquat em dosagem única aumenta os teores foliares de cálcio.

A aplicação parcelada do cloreto de mepiquat promove aumento do índice SPAD de clorofila, dos teores foliares de magnésio e da produtividade do algodão em caroço.

\section{Agradecimentos}

À FAPESP por todo apoio prestado à realização deste trabalho.

\section{Referências}

AQUINO L. A.; AQUINO, R. F. B. A.; SILVA, T. C.; SANTOS, D. F.; BERGER, P. G. Aplicação do fósforo e da irrigação na absorção e exportação de nutrientes pelo algodoeiro. Revista Brasileira de Engenharia Agrícola Ambiental, Campina Grande, v. 16, n. 4, p. 355-361, 2012.

AZEVEDO, D. M. P. de; BEZERRA, J. R. C.; SANTOS, J. W.; DIAS, J. M.; BRANDÃO, Z. N. Efeito do parcelamento do cloreto de mepiquat em algodoeiro irrigado no nordeste brasileiro. Revista Brasileira de Oleaginosas e Fibrosas, Campina Grande, v. 8, n. 3, p. 823-830, 2004.

BANZATTO, D. A.; KRONKA, S. do N. Experimentação agrícola. Jaboticabal: FUNEP, 2006. 237 p.

BELTRÃO, N. E. M.; AZEVEDO, D. M. P. Defasagem entre as produtividades real e potencial do algodoeiro herbáceo: limitações morfológicas, fisiológicas e ambientais. Campina Grande: Embrapa Algodão, 1993. 108 p. (Embrapa CNPA. Documentos, 39).

BOGIANI, J. C.; ROSOLEM, C. A. Sensibilidade de cultivares de algodoeiro ao cloreto de mepiquat. Pesquisa Agropecuária Brasileira, Brasília, v. 44, n. 10, p. 12461253, 2009.

CARVAlHO, L. H.; CHIAVEGATO, E. J.; CIA, E.; KONDO, J. I.; SABINO, J. C.; PETTINELLI JÚNIOR, A.; BORTOLETTO, N.; GALLO, P. B. Fitorreguladores de crescimento e capação na cultura algodoeira. Bragantia, Campinas, v. 53, n. 2, p. 247-254, 1994.
CARVALHO, M. C. S.; FERREIRA, G. B. Calagem e adubação do algodoeiro no cerrado. Campina Grande: Embrapa Algodão, 2006. 36 p. (Circular técnica, 92).

CASSMAN, K. G. Cotton. In: BENNETT, W. F. (Ed.). Nutrient deficiencies \& toxicities in crop plants. Saint Paul: APS Press, 1993. cap. 10, p. 111-119.

CLAWSON, E. L.; COTHREN, J. T.; BLOUIN, D. Nitrogen fertilization and yield of cotton in ultra-narrow and conventional row spacings. Agronomy Journal, Madison, v. 98, n. 1, p. 72-79, 2006.

COMPANHIA NACIONAL DE ABASTECIMENTO CONAB. Acompanhamento de safra brasileira: grãos, nono levantamento, junho de 2013. Brasília: Conab, 2013. $31 \mathrm{p}$.

CÖSER, A. C.; MARASCHIN, G. E. Produção e qualidade de forragem de milheto comum e sorgo cv. Sordam NK sob pastejo. Pesquisa Agropecuária Brasileira, Brasília, v. 16, n. 3, p. 397-403, 1981.

FERREIRA, D. F. SISVAR: A computer statistical analysis system. Ciência e Agrotecnologia, Lavras, v. 35, n. 6, p. 1039-1042, 2011.

FERREIRA, M. M. M.; FERREIRA, G. B.; FONTES, P. C. R.; DANTAS, J. P. Índice SPAD e teor de clorofila no limbo foliar do tomateiro em função de doses de nitrogênio e da adubação orgânica, em duas épocas de cultivo. Revista Ceres, Viçosa, v. 53, n. 305, p. 83-92, 2006.

FONTES, P. C. R. Diagnóstico do estado nutricional de plantas. Viçosa: UFV, 2001. $122 \mathrm{p}$.

GUIDELI, C.; FAVORETO, V.; MALHEIRIOS, E. B. Produção e qualidade do milheto semeado em duas épocas e adubado com nitrogênio. Pesquisa Agropecuária Brasileira, Brasília, v. 35, n. 10, p. 2093-2098, 2000.

HODGES, H. F.; REDDY, V. R.; REDDY, K. R. Mepiquat chloride and temperature effects on photosynthesis and respiration of fruiting cotton. Crop Science, Madison, v. 31, n. 5, p. 1301-1308, 1991.

MADEIRA, A. C.; CARNEIRO, M.; MARQUES, P.; MADEIRA, M. Avaliação do estado de nutrição de plantas jovens de Eucalyptus globulus por análise foliar e espectroradiométrica. Revista de Ciências Agrárias, Belém, v. 32, n. 1, p. 13-26, 2009.

MALAVOLTA, E. A.; VITTI, G. C.; OLIVEIRA, A. S. Avaliação do estado nutricional das plantas: princípios e aplicações. Piracicaba: POTAFOS, 1997. 201 p.

MEREDITH JUNIOR, W. R.; WELLS, R. Potential for increasing cotton yields through enhanced partitioning to reproductive structures. Crop Science, Madison, v. 29, n. 3, p. 636-639, 1989. 
NAGASHIMA, G. T.; MIGLIORANZA, E.; MAURUR, C. J.; YAMAOKA, S.; SILVA, J. G. R. Desenvolvimento do algodoeiro em resposta a modo de aplicação e doses de cloreto de mepiquat via sementes. Ciência Rural, Santa Maria, v. 40, n. 1, p. 7-11, 2010.

NEVES, O. S. C.; CARVALHO, J. G.; MARTINS, F. A. D.; PÁDUA, T. R. P.; PINHO, R. J. Uso do SPAD-502 na avaliação dos teores foliares de clorofila, nitrogênio, enxofre, ferro e manganês do algodoeiro herbáceo. Pesquisa Agropecuária Brasileira, Brasília, v. 40, n. 5, p. 517-521, 2005.

OLIVEIRA, F. de A. de; MEDEIROS, J. F. de; OLIVEIRA, F. R. A. de; FREIRE, A. G.; SOARES, L. C. da S. Produção do algodoeiro em função da salinidade e tratamento de sementes com regulador de crescimento. Ciência Agronômica, Fortaleza, v. 43, n. 2, p. 279-287, 2012.

RAIJ, B. V.; QUAGGIO, J. A. Métodos de análises de solos para fins de fertilidade. Campinas: Instituto Agronômico, 1983, 31 p. (Boletim técnico, 81).

REDDY, A. R.; REDDY, K. R.; HODGES, H. F. Mepiquat chloride (PIX)-induced changes in photosynthesis and growth of cotton. Plant Growth Regulation, New York, v. 20, n. 3, p. 179-183, 1996.

ROSOLEM, C. A. Problemas em nutrição mineral, calagem e adubação do algodoeiro. Botucatu: UNESP, 2001. 16 p. (Informações Agronômicas, 95).

ROSOLEM, C. A.; ECHER, F. R.; LISBOA, I. P.; BARBOSA, T. S. Acúmulo de nitrogênio, fósforo e potássio pelo algodoeiro sob irrigação cultivado em sistemas convencional e adensado. Revista Brasileira de Ciência do Solo, Viçosa, v. 36, n. 2, p. 457-466, 2012.

ROSOLEM, C. A.; OOSTERHUIS, D. M.; SOUZA, F. S. de. Cotton response to mepiquat chloride and temperature. Scientia Agricola, Piracicaba, v. 70, n. 2, p. 82-87, 2013.

SANTOS, H. G. dos; JACOMINE, P. K. T.; ANJOS, L. H. C. dos; OLIVEIRA, V. A. de; OLIVEIRA, J. B.; COELHO, M. R.; LUMBRERAS, J. F.; CUNHA, T. J. F. (Ed.). Sistema brasileiro de classificação de solos. 2. ed. Rio de Janeiro: Embrapa Solos, 2006. 306 p.
SILVA, A. V. Espaçamentos ultra-adensado, adensado e convencional com densidade populacional variável em algodoeiro. 2002. Dissertação (Mestrado em Agricultura) - Universidade de São Paulo, Piracicaba.

SILVA, N. M. Nutrição mineral e adubação do algodoeiro no Brasil. In: CIA, E.; FREIRE, E. C.; SANTOS, W. J. Cultura do Algodoeiro. Piracicaba: POTAFÓS, 1999. p. 57-92.

SILVA, N. M.; RAIJ, B. van. Fibrosas. In: RAIJ, B. van; CANTARELlA, H.; QUAGGIO, J. A.; FURLANI, A. M. C. (Ed.). Recomendações de adubação e calagem para o Estado de São Paulo. 2. ed. Campinas: Instituto Agronômico/Fundação IAC, 1997. 107-111 p. (Boletim técnico, 100).

SOUZA, F. S. Ação de reguladores de crescimento no algodoeiro em função da ocorrência de chuvas, temperatura e adjuvantes. 2007. Tese (Doutorado em Agricultura) - Universidade Estadual Paulista, Botucatu.

SOUZA, J. C.; BELTRÃO, N. E. M. Fisiologia. In: BELTRÃO, N. E. M. O agronegócio do algodão no Brasil. Brasília: Embrapa-CTT, 1999. v. 1, p. 87-116.

TAIZ, L.; ZEIGER, E. Fisiologia vegetal. Porto Alegre: Artmed, 2009. $722 \mathrm{p}$.

ZANQUETA, R.; FURLANI JÚNIOR, E.; PANTANO, A. C.; SOUZA, R. A. R. Modos de aplicação de regulador de crescimento com diferentes densidades de plantas em cultivares de algodão herbáceo (Gossypium hirsutum L. var. latifolium Hutch.). Acta Scientiarum. Agronomy, Maringá, v. 26, n. 1, p. 97-105, 2004.

ZOTARELLI, L.; CARDOSO, E. G.; PICCININ, J. L.; URQUIAGA, S.; MICHAEL R. B.; TORRES, E.; ALVES, B. J. R. Calibração do medidor de clorofila Minolta SPAD-502 para avaliação do conteúdo de nitrogênio do milho. Pesquisa Agropecuária Brasileira, Brasília, v. 38, n. 9, p. 1117-1122, 2003. 